\section{Earthquake Mechanism and}

\section{Displacement Fields} Close to Fault Zones

\section{REPORT ON THE SIXTH GEOP RESEARCH CONFERENCE}

T HE Sixth Geodesy/Solid Earth and Ocean Physics (GEOP) Research Conwas held on February 4-5, 1974, at the Institute of Geophysics and Planetary Physics, University of California, San Diego, in La Jolla, California. It was attended by about 100 persons.

James N. Brune, program chairman, opened the conference and delivered the introductory address, a somewhat extended version of which is printed elsewhere in this issue. Brune's paper and the following summaries of the sessions constitute a report of the conference.

\section{First Session}

Panel on Geologic and Tectonic Aspects

Chairman: C.R. Allen (California Institute of Technology)

Members: C.B. Raleigh (U.S. Geological Survey), J.C. Crowell (University of California, Santa Barbara), M.G. Bonilla and G. Plafker (U.S. Geological Survey)

In his brief introductory remarks the chairman stressed the importance of actual field and laboratory measurements in designing realistic models of earthquake mechanisms.

C.B. Raleigh, in the first formal presentation, discussed the implications of recent rock mechanics experiments in the light of the dilatancy model that $A$. Nur has used to explain the $V p / V s$ anomalies preceding earthquakes. Crack propagation stress depends on the internal fluid pressure within the cracks. If the pore pressure is greater than the liquid-vapor equilibrium pressure, opening of cracks will cause the pressure to drop and stabilize the crack. Thus the adjacent cracks will propagate, which will cause the dilatant region to grow, depending primarily on the stresses in the rock. One conclusion is that the pore pressures at the time of earthquakes will be near the liquid-vapor equilibrium pressure. Also, since the total stresses control the dimensions of the dilatant region, thrust faults might be expected to have dilatant volumes that are large compared with those for strike slip faults.

This report was prepared by C.R. Allen, Jon Berger, Ivan I. Mueller, J.C. Savage, and $J$. Weertman. Material contained herein should not be cited.
J.C. Crowell emphasized that rocks subject to earthquakes in California have been involved in a long and complex history that ought to be kept in mind as we at tempt to understand events before, during, and after earthquakes. In looking at the $S$ an Andreas system through time, the geologic record discloses that major blocks have moved laterally on near-vertical fault zones, but that these faults are many and are by no means straight or parallel. Blocks along straight faults move easily with pure strike slip, but where the faults curve, two kinds of bends occur, restraining bends and releasing bends. Rocks inside curves of restraining bends have been severely deformed through horizontal shortening for long periods, whereas those outside such bends have been locally stretched. Releasing bends result in the opening of holes, sags, or pullaparts. The Los Angeles basin was probably formed as a pull-apart depression in Miocene time, and, as in the Salton trough today, volcanics formed the floor as an irregular pull-apart opened and sediments concomitantly poured into it. In the California borderland, fault divergence and convergence, in combination with pullapart depressions and restraining-bend uplands, provide a simple geometric model of the tectonics. In summary, the boundary between the North American and Pacific plates ought to be envisaged as a broad zone a few hundred kilometers wide that sits astride the present San Andreas fault. This broad zone, through late Cenozoic time, has been active in complex ways that are now being geologically documented.

The detailed description of surface faulting during historic earthquakes was the subject of M.G. Bonilla's remarks. He illustrated these with both photographs and detailed maps of a number of significant historic earthquakes associated with surface faulting. The principal conclusions he drew were the following.

1. There is a poor correlation between magnitude and the surface length of rupture.

2. The correlation between maximum displacement and magnitude is moderately good.

3. Fault zones have appreciable widths, which must be taken into account in engineering considerations.

4. Subsidiary fractures, although usually quite small, can occur many kilometers from the main fault. In the Assam earthquake of 1897 , one subsidiary break 
was $80 \mathrm{~km}$ from the presumed main fault.

5. Contrary to earlier conclusions, the zones affected by the main and subsidiary fractures are as wide for strike slip faults as for other fault types.

6. Map patterns of surface faulting are usually very complex.

The great 1899 earthquake near Yakutat Bay in Alaska was the subject of G. Plafker's paper. On the basis of recent field work, he reinterpreted many of the conclusions contained in the classic 1901 study by Tarr and Martin. Following are his major points.

1. Seismicity and deformation are centered along the south front of the Chugach and St. Elias mountains and probably extend for at least $160 \mathrm{~km}$, and possibly $250 \mathrm{~km}$, west of the Yakutat Bay area.

2. Earthquake-related deformation was primarily uplift relative to sea level and probably involved slip on the complex system of east-trending, north-dipping thrust faults that extend inland from the Gulf of Alaska to the Chugach-St. Elias fault. Absence of an oceanic tsunami suggests that there was probably no significant vertical uplift offshore.

3. Vertical tectonic displacements in the Yakutat Bay area do not define a system of local fault-bounded blocks, as was inferred by Tarr and Martin. Instead, they define a broad regional upwarp 50 $\mathrm{km}$ long by $30 \mathrm{~km}$ wide, with an average uplift of 2-3 m. Extreme local uplifts of as much as $14.2 \mathrm{~m}$ occurred at a small fault-bounded block that is superimposed on the broader upwarp.

4. Swarms of fractures that Tarr and Martin thought to be subsidiary faults at the Nunatak and elsewhere were caused instead by large-scale earthquake-triggered slides.

5. According to this reappraisal, the 1899 earthquake sequence does not fill a possible seismic gap east of the focal region of the 1964 Alaska earthquake. If so, this part of the Alaskan continental margin may have a relatively high potential for a future major earthquake.

\section{Second Session}

\section{Panel on Observational Data}

Chairman: J.C. Savage (U.S. Geological Survey)

Members: R.O. Castle, R.D. Nason, and M.D. Wood (U.S. Geological Survey)

The phenomenon of fault creep (aseismic fault slip) has been observed directly in Turkey and very recently (according to a comment by G.C.P. King) in Iran. The most extensive observations, however, have been made along the San Andreas fault system in central California, and it was those observations that were reviewed by R.D. Nason. The observed fault creep at some sites is episodic, with several millimeters of fault slip occurring in a period of a few hours, followed by weeks in which very little, if any, slip occurs. At other sites, slip is essentially steady with only minor fluctuations in the creep rate.
Studies of the episodic creep events indicate that the events propagate from site to site at velocities of the order of a few kilometers per day, suggesting spreading surfaces of failure. The observation that rates of fault creep are virtually identical with the observed geodetic deformation across a zone at least $10 \mathrm{~km}$ wide suggests that fault creep must extend to appreciable depth (say $20 \mathrm{~km}$ or more) on the fault. However, the question of whether creep at depth is eventful or is steady has not been resolved.

J.C. Savage reviewed the geodetic measurements of horizontal deformation. The measured horizontal displacement fields associated with earthquakes are generally consistent with simple dislocation models of faulting, although the detailed agreement is never very good. Two measurements of relative plate motion across the San Andreas fault were contrasted: Astronomic azimuths observed in the vicinity of Hollister, California, indicate a linear-intime right-lateral motion of $33 \mathrm{~mm} / \mathrm{yr}$ across a $50-\mathrm{km}$-wide zone in the period 1884-1962. This motion is almost wholly accounted for by rigid-block motion. Optical parallax measurements in 1970 and 1972 by V. Vacquier and R.E. Whiteman across what is thought to be the fault trace in the Gulf of California suggest no appreciable relative motion other than perhaps uniform rotation across a $25-\mathrm{km}$-wide zone, although other interpretations are possible. A review of the measurements of the California geodimeter network substantiates the suggestion of R.W. Greensfelder and J.H. Bennett that the measurements of line length versus time generally exhibit a positive curvature (i.e., $d^{2} L / d t^{2}$ $>0)$ throughout the state. It is not yet clear whether this is an artifact of changes in observational procedures or a real physical phenomenon. Although measurements of strain accumulation along the San Andreas fault are individually suspect, taken all together they indicate that the rate of tensor shear strain accumulation is about $0.3 \mu$ strain/yr. W.R. Thatcher discussed the measured strain accumulation near Fort Ross, California, as deduced from triangulation surveys in 1874,1906 , 1930 , and 1969. He showed that the data indicated $4 \mathrm{~m}$ of slip to a depth of about $10 \mathrm{~km}$ at the time of the 1906 earthquake, followed by afterslip of about $3 \mathrm{~m}$ in the depth range from $10 \mathrm{~km}$ to $20 \mathrm{~km}$ or deeper in the period 1906 (postearthquake) to 1930 . No significant deformation was detected in the period 1930-1969. Savage suggested that the apparent afterslip might equally well be explained by relaxation of a viscoelastic subcrustal layer, as was proposed by $A$. Nur and G. Mavko to account for postseismic movements following the 1946 Nankaido earthquake.

Measurements of vertical deformation as detected by geodetic leveling were discussed by R.O. Castle. The vertical deformation observed at the time of an earthquake can be rather precisely reproduced by simple dislocation models. However, the vertical deformation that is known to precede some earthquakes is not understood. Castle reviewed the data that indicated an anomalous 50-mm uplift near Niigata, Japan, five years before the magnitude 7.5 earthquake there. The data would appear to be consistent with the dilatancy theory. New data for vertical deformation near San Fernando, California, in the decade preceding the magnitude 6.5 earthquake there were also presented. Level surveys repeated in 1961,1964 , 1965, 1968, 1969, and 1971 (postearthquake) furnished an exceptionally fine data base for dectection of vertical movement. Several identifiable pulses of anomalous uplift of as much as $80 \mathrm{~mm}$ could be detected at various times in the 1961-1971 period, any one of which might be premonitory to the San Fernando earthquake. However, the largest anomaly, about $200 \mathrm{~mm}$, occurred near Palmdale, California, between 1961 and 1964 and appears to be associated with the San Andreas fault. N.L. Morrison discussed the possibility that vertical deformation of the amount associated with these anomalies could be attributed to accumulated error in the level surveys. Random errors in first-order levels accumulate as $a L^{1 / 2}$ where $a$ is less than 1 $\mathrm{mm} / \mathrm{km}^{1 / 2}$ and $L$ is the length of the surveyed section. Observation and computation procedures are such that known causes of systematic error are eliminated by cancellation, calibration, or correction. Existence of significant systematic error is unlikely on these lines of length less than $100 \mathrm{~km}$. Thus the reported anomalies appear to be well above expected errors.

Tide gages along seismically active coasts offer the possibility of obtaining continuous records of preseismic, coseismic, and postseismic vertical deformation. M.D. Wood reviewed these data. Good records of the coseismic elevation changes have been obtained at the time of several great seismic thrusts. The records apparently do not show significant vertical motion immediately preceding (e.g., a few hours before) the earthquakes. Whether premonitory uplift occurs years before the earthquake is difficult to ascertain because of the inherent noise in the tidal record due to changes in water temperature and salinity, prevailing winds, and barometric pressure. The reported abrupt change in sea level at Nezugaseki, Japan, five years before the Niigata earthquake is seen only after corrections for the above parameters are made; the absence of any anomaly on the uncorrected record makes the existence of that reported precursor dubious.

Finally, A.M. Dziewonski reported on compressive deformation at the source that apparently preceded and accompanied two deep-focus earthquakes (Columbia, July 31, 1970, and Peru-Bolivia, August 15, 1963) studied by him and F. Gilbert. The conclusion was based on the low-frequency behavior of the seismic moment tensor determined from several hundred seismograms. The conclusion that the compression was actually precursive was based on extrapolation of the ob- 
served Fourier spectrum to the lower frequencies.

\section{Third Session}

\section{Panel on Theoretical Models}

\section{Chairman: J. Weertman (Northwestern)}

Members: J.B. Walsh (Massachusetts Institute of Technology), A. Nur (Stanford), R. Alewine (California Institute of Technology), C.-Y. King (U.S. Geological Survey)

Contributors: D. Turcotte (Cornell), D. Oldenburg (Institute of Geophysics and Planetary Physics, University of California, La Jolla)

In the introduction of the session, $J$. Weertman noted that changes in displacements around faults can be used to make a rough estimate of the amount of slip on a fault and the size and position of the fault area that has slipped. The estimates are made by comparing observed displacements with displacements calculated from different dislocation models. In only one of the models developed so far can the surface displacements be transformed mathematically to give information such as the dislocation density on a fault. This is the model of an infinitely long, vertical strike slip fault that contains infinitely long screw dislocations that lie parallel to the earth's surface. Let $w(y)$ be the surface displacement, where $y$ is the distance from the fault in a positive direction. Apart from a constant term, the slippage displacement $D(x)$ across the fault at a depth $x$ is equal to $2 \operatorname{Re}[w(i x)]$ and the integrated shear stress $\int \tau(x) d x$ that acts across the fault is equal to $-\mu \operatorname{Im}[w(i x)]$. The quantity $\mu$ is the shear modulus. The dislocation density $B(x)$ is equal to $-2 \mathrm{Im}$ $\left[w^{\prime}(i x)\right]$ and the shear stress $\tau(x)$ across the fault is equal to $-\mu \operatorname{Re} w^{\prime}(i x)$, where $w^{\prime}(y)=d w / d y$. In a practical situation these relationships permit a very rough estimate to be made for $D(x)$ and the integrated shear stress but are virtually useless for obtaining the other quantities.

Weertman also pointed out that the water flow paths around an edge dislocation on a fault in the model of Nur and Booker should be modified if the rock surrounding the fault is impervious to water when it contains no cracks. Such rock will contain cracks and water will flow through the cracks. The water pressure at any point will be the overburden pressure less the most tensile stress (or plus the least compressive stress) component of the dislocation stress field. The effective permeability of fluid flow also will be anisotropic in character because of the nonhydrostatic stress components. If the degree of anisotropy is high, fluid will be forced to flow along the fault plane.

J.B. Walsh showed that surface displacements found by using standard geodetic techniques can be used to estimate parameters such as fault depth and dip angle, energy release, seismic moment, and average stress drop. Direct inversion of the displacement field for the purpose of determining the distribution of the stress change on the fault is not practical because of the uncertainty in the measurements of the surface displacement. Much of this ambiguity in the inversion is inherent in the method. Instead of inverting the surface displacement field, a displacement distribution or stress distribution on the fault is assumed, and the surface displacements are calculated by using elasticity theory. These theoretically calculated surface displacements are fitted to the observed displacements by adjusting a free parameter, usually the fault depth. Values of fault parameters estimated by using different models may differ by a factor of 2.

A. Nur pointed out that there are at least two different time-dependent processes involved in the change of displacement fields near earthquake faults. One of these involves the flow of water and the other the viscoelastic behavior of rock. The postseismic displacement changes that followed the Nankaido earthquake displayed a complicated time behavior for several years at the various observation stations. A simple model of sudden faulting in an elastic lithosphere that rests on viscoelastic asthenosphere can be used to demonstrate that this postseismic deformation is caused by the relaxation in the viscoelastic asthenosphere. Analysis of geodetic, seismic, and gravity data from the Matsushiro earthquake swarm shows remarkable agreement with the features predicted by the theory of dilatancy and water flow. It appears that the (upward) vertical displacements at the surface cannot be explained by the dislocation model that explains the horizontal displacements. The gravity data indicate that during the early stages of the earthquake swarm the vertical displacements were accompanied by a reduction of mass underneath the area that was displaced upward. In the later stages of the swarm the mass in this region increased markedly. Nur believes that these observations prove that dilatancy and fluid flow are responsible for the vertical deformation. He concludes that gravity measurements may be sensitive enough to changes in dilatant expansion to be used as a method for studying the phenomenon of dilatancy at earthquake faults.

R.W. Alewine III described his systematic method for the estimation of fault model parameters. A three-dimensional fault model composed of many appropriately oriented fault elements was used to approximate the faulting of the San Fernando, California, earthquake. The geometry of the fault system was fixed to conform to all the geophysically observable properties of this event. A linear inversion scheme was used to simultaneously estimate in an optimum sense the absolute slip along each of the fault elements given the geometry and a set of observed displacement data. A means of mapping the estimated variance in the observed data into uncertainties in the fault model parameters was given and examples were shown. The displacement function along the fault surface for this earthquake was found to vary considerably with depth, indicating the nonuniformity of the preexisting strain field.

Chi-Yu King summarized observations made on a laboratory model of a seismic strike slip fault. The model consists of spring-connected weights around a circular cylinder. The circular configuration of the model thus eliminates end effects. His model observations suggest that nonuniform friction along a fault is important for the generation of earthquakes of various magnitudes but that the nonuniformity of the friction does not need to be very large. The shear stress drop associated with small and moderate earthquakes is very small in comparison with the total shear stress that exists before the earthquake. That is, the occurrence of small and moderate earthquakes does not perturb greatly the stress level at the fault. The stress drops vary widely in magnitude as a result of a relatively small nonuniformity in the friction; they generally increase in magnitude with the size of the earthquake. King also suggested that ruptures may have a preferred direction of propagation along a curved fault in the earth that has different types of material on either side of the fault. $\mathrm{He}$ believes that processes other than frictional sliding that can change the level of the local stresses are required to explain the aftershock and fault creep phenomena. These processes might be viscous sliding and the diffusion of fluids.

D.L. Turcotte presented a cyclical model for the accumulation and release of strain adjacent to a strike slip fault. His model is based on the assumption that the upper $15 \mathrm{~km}$ of the plate acts in a brittle manner and that the lithosphere beneath this brittle region is deformed plastically. The model considers a rectangular shaped plate that is bordered on two parallel sides by strike slip faults (transform faults), on one side by a spreading ridge and on the opposite side by a trench. A two-dimensional crack analysis yields the strain field in the lithosphere when the fault is locked to a prescribed depth. The strain field was shown to extend only to a distance of the order of the length of the locked fault away from the fault. The linear increase of stress on the locked fault and the quadratic increase in stored elastic energy was obtained. The results were compared with measurements of strain accumulation, but the scatter in the data makes it difficult to discriminate between alternative models.

D. Oldenburg described and later demonstrated a dynamic laboratory model of oceanic ridges and transform faults. The model uses hot wax that is simultaneously pulled in a horizontal direction and cooled at the upper surface.

\section{Fourth Session}

Panel on Instrumentation and the Future

Chairman: Jon Berger (Institute of Geophysics and Planetary Physics, University of California, La Jolla) 
Members: S.W. Smith (University of Washington), G.C.P. King (Cambridge), J. Levine (National Bureau of Standards, Boulder), P. Bender (University of Colorado)

Contributors: C. Beaumont (Institute of Geophysics and Planetary Physics, University of California, La Jolla), P.F. MacDoran (Jet Propulsion Laboratory), C.C. Counselman (Massachusetts Institute of Technology), J.P. Murphy and J.W. Siry (NASA), M.J.S. Johnston (U.S. Geological Survey), K.L. Cook (University of Utah)

After introductory remarks by the Chairman, S.W. Smith opened by describing a recent engineering evaluation of several types of conventional quartz tube strain meters. It was shown that the effects of humidity are much larger than might have been expected and that the nonlinear effects of lateral vibrations of the quartz tube are a significant source of long-period noise. Tests were run with quartz strain meters and a laser interferometer on the same piers. Temperature corrections applied to the quartz instruments were adequate to produce a good correspondence between laser and quartz instruments, but changes in humidity between $50 \%$ and $100 \%$ produced transient strains of $10^{-6}$ and a time constant of about 20 hours. The strain was recoverable with the same time constant when the humidity was reduced. This observation leads to the conclusion that humidity may be a significant source of apparent seasonal variations observed with quartz strain meters and may be responsible for the large transient strains observed in new installations. Typical deep mine installations are in a constant $100 \%$ humidity situation, and hence the effect may not be of significance there.

Smith also described a borehole instrument consisting of five miniature quartz strain meters in a compliant canister that has recently been developed and installed at Mina, Nevada. The installation is in a shallow hole within the mine, which contains conventional quartz strain meters; thus a direct comparison of tidal and secular strains recorded on these different types of instruments will soon be available. The borehole instrument had a drift rate of approximately $10^{-8}$ per day after 30 days, apparently as a result of the curing of grout used in the installation. Earth tides are clearly visible.

Some very encouraging results from a two-color geodimeter under development at the University of Washington were also reported. Over a $10-\mathrm{km}$ baseline, the standard deviation of distance measurements over several hours' time was $1 \times 10^{7}$. Longer tests that will include a wide variety of meteorological conditions are now under way and will provide an estimate of the absolute accuracy of this instrument. Field tests in which a microwave link was operated simultaneously show that the effects of water vapor on the distance measurement can be significantly reduced. Results to date indicate that this instrument will produce an order of magnitude improvement in distance measurement over a conventional geodimeter.

G.C.P. King reported on results obtained with invar wire strain meters in a variety of configurations. Extensive work at the Queensburg Tunnel in Yorkshire, England, revealed significant effects of the tunnel cavity on the strain measurements. Those instruments aligned along the axis of the tunnel were less affected than those at right angles. King reported on work that the Cambridge group is doing along the Anotolian fault in Iran.

J. Levine reviewed the state of instrumentation of laser strain meters including the $I_{2}$ laser system of Cambridge University, the $800-\mathrm{m}$ surface installations of the University of California, San Diego, and his methane-stabilized system installed near Boulder, Colorado. He emphasized that there were several different approaches to the interferometric measurement of strain made possible through the use of lasers, and that if care were taken, they would work equally well. He described the results of an intercomparison of the observations of laser strain meters of different design at three different sites and showed that the measured noise levels agreed to within $10 \mathrm{~dB}$ over a frequency range of $10^{8}$ to $10^{2} \mathrm{~Hz}$. These observations were free of spurious strain steps, large strain episodes, and other such anomalous behavior. In conclusion, Levine conceived with Smith that the advantages of laser interferometric strain measurements over more conventional types more than compensated for their higher cost. Further, he said that the construction of these instruments, which once involved 'state of the art' complexity, had now become a routine matter.

Extraterrestrial methods for determining crustal movements in seismic zones and for directly measuring the relative motions of tectonic plates were discussed by P.L. Bender. Independent station radio interferometry, laser distance measurements to artificial satellites, and laser measurements to the moon all appear capable of achieving 1- to 3-cm accuracy for determining the three-dimensional location of points on the earth's surface. Observations from a movable station over a period of from a few days to a month would be used with those from already existing fixed stations to determine the movable station location. All three techniques appear desirable for providing a basic framework of control points around and within seismic zones, and intercomparisons at these points would provide accurate crosschecks between the methods. A coarse grid of points within the framework at spacings of down to perhaps $100 \mathrm{~km}$ could be remeasured each year by radio interferometry or satellite ranging, provided that the costs can be kept low enough. In regions of particular interest, more closely spaced points would be tied into the grid by ground survey techniques.

The extraterrestrial methods also appear capable of accurately measuring the relative motions of 2 or 3 points on each of the major tectonic plates within a fairly short period of time. This would provide a valuable check on the plate motion models used in trying to understand strain accumulation in seismic zones and would indicate whether appreciable strain accumulation is taking place away from the main seismic zones. In addition, information on whether large aseismic motions accompany some major earthquakes can be obtained from the extraterrestrial methods by accurately observing changes in the polar motion of the earth.

There were seven contributors to this session, beginning with C. Beaumont, who presented the results of work by himself and Berger that examined the changes in the earth tide admittance to be expected to accompany dilatancy. Numerical solutions for the earth tide on a model earth with dilatant crustal inclusions indicate that up to $60 \%$ changes in the strain tide and $100 \%$ changes in the tilt tide will result from a 15 to $20 \%$ reduction in the ratio $V p / V s$, the seismic $p$ to $s$ velocity in the inclusion. Further, detectable changes will occur up to a distance of 1.5 times the typical dimension of the dilatant inclusion. Monitoring of the earth tide was therefore suggested as a sensitive and continuous method of earthquake prediction if such dilatancy precedes earthquakes. The time dependence of the tidal signal due to dilatancy is identical to that of the $V p / V_{s}$ ratio, because both depend on changes of the elastic moduli in the dila$\tan t$ zone. A search of the tidal strain data for the past three years from the laser strain meters at the Piñon Flat Geophysical Observatory yields no existence of anomalous changes in the tidal signal, nor have there been any earthquakes in the vicinity of the observatory. The practical limits of detectability for the method are about $\pm 2 \%$ change in strain tide admittance for a one-month period.

P.F. MacDoran reviewed the progress his lab has made in very long baseline radio interferometry (VLBI). He pointed out some advantages that this technique has over the other extraterrestrial ranging methods and outlined plans for a Southern California network of such stations. Feasibility experiments conducted over a $10-\mathrm{km}$ path have demonstrated an accuracy of a few centimeters for threedimensional determinations of relative position. Operation on longer baselines will require calibration for atmospheric earth rotational, and astronomical effects, but MacDoran indicated that studies have shown that three-dimensional separation of antennas up to several hundred kilometers may be determined to a few centimeters' accuracy.

C.C. Counselman presented some results of VLBI experiments performed between April 1972 and March 1973 with the Haystack Observatory in Massachusetts and the Goldstone Tracking Station in California. Results for the baseline length of $3900 \mathrm{~km}$ yielded an rms spread of under $25 \mathrm{~cm}$. The corresponding fractional uncertainty of about 6 parts in $10^{8}$ is one of the lowest ever achieved in geod- 


\section{EDITED BY JOHN BIRD AND BRYAN ISACKS}

\section{FOREWORD BY ORSON L. ANDERSON}

\section{LIST PRICE $\$ 5.00$}

20\% Discount to AGU Members

Selected Papers Reprinted From The Journal Of Geophysical Research

Published By

AGU 1707 L St., N.W. Washington, D.C. 20036

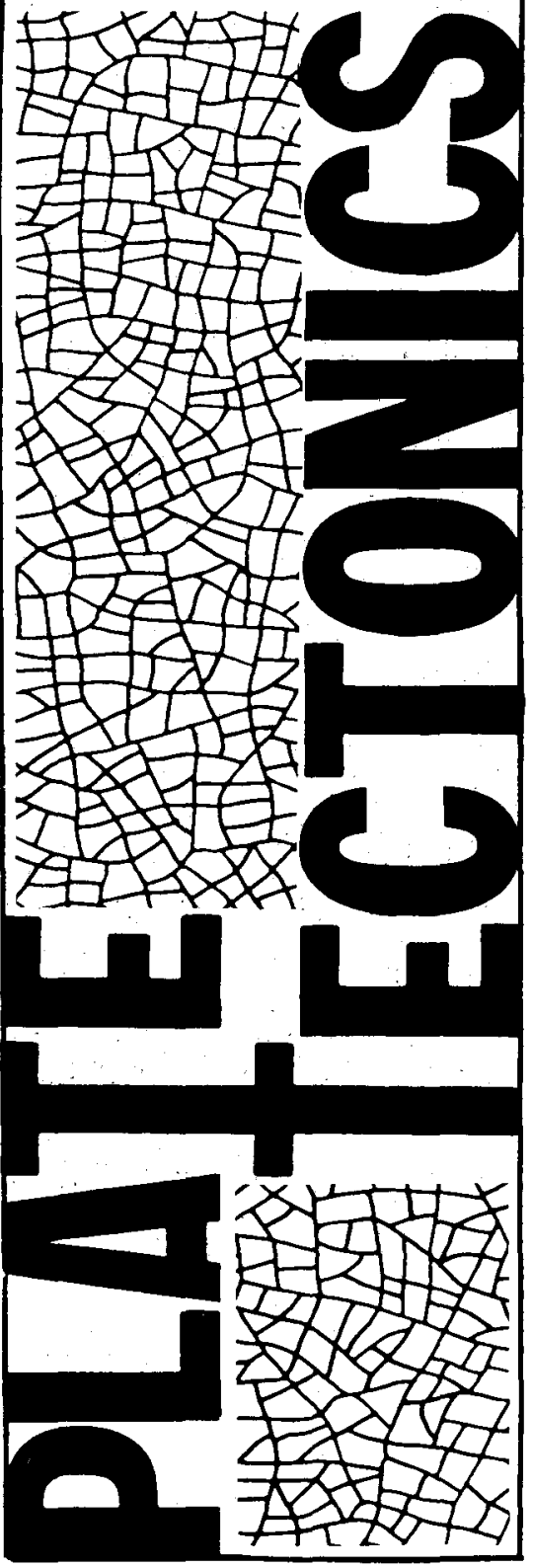

esy. The effects of solid-earth tides were also detected, but no useful estimate of their amplitude was extracted. Counselman estimated that improved radiointerferometric instrumentation could soon provide displacements, both horizontal and vertical, with uncertainties that range from 4 parts in $10^{7}(2 \mathrm{~mm})$ over a distance of $5 \mathrm{~km}$ to 4 parts in $10^{9}(2 \mathrm{~cm})$ over $5000 \mathrm{~km}$. Determinations of such accuracy could be made with small ( $\$ 3-\mathrm{m}$ diameter) transportable antennas in combination with any of the existing, large, fixed antennas.

J.P. Murphy discussed the feasibility of regional crustal motion determination by using laser ranging to artificial satellites and using radio stars by means of the very long baseline interferometry. Laser ranging results over a baseline of about $1900 \mathrm{~km}$ between Quincy on the North American plate and San Diego on the Pacific plate indicate accuracies of about $25 \mathrm{~cm}$. Planned tracking improvements and improved satellite targets will result in future measurement accuracies of about 2 or 3 cm.

J.W. Siry reported on the NASA Earth and Ocean Physics Applications Program (Eopap). This program includes a number of missions that are expected to provide new knowledge about earthquake mechanisms and displacement fields close to fault zones. Accurate measurements of crustal motions will be made by Lageos and Geopause missions. Geos-C, Seasat and $G$ ravsat will provide information about the fine structure of the gravitational field and, in turn, of tectonic plate structure.

\section{Pacific Northwest Region Call for Papers}

O RGANIZERS of the TwentyFirst Annual Meeting of AGU's Pacific Northwest Region to be held October 17-18, 1974, have issued a call for papers for special sessions on the topics 'Nuclear Energy and Geophysics,' 'Geothermal Energy Exploration,' and 'Mid-Latitude Auroral
The Lageos satellite, to be launched in 1976, will be a sphere about $0.6 \mathrm{~m}$ in diameter, weighing about $380 \mathrm{~kg}$ and covered with an array of about 600 retroreflectors. It is now planned that its nearly circular orbit will have an altitude of about $5700 \mathrm{~km}$ and an inclination of approximately $110^{\circ}$. It will be tracked by a set of lasers having accuracy capabilities of $10 \mathrm{~cm}$ or better. It is anticipated that crustal motion measurement uncertainties of the order of $2-5 \mathrm{~cm}$ per year will be achievable with this system.

Geos-C will provide altimeter measures of the ocean geoid with 5-m accuracy globally and 2-m accuracy locally. Seasat will provide improved capabilities of this type.

Geopause will open up the possibility of monitoring displacement fields close to fault zones at several hundred points.

Gravsat will yield information about the global geoid with $10 \mathrm{~cm}$ accuracy and a spatial resolution of about $2^{\circ}$ or $3^{\circ}$.

M.J.S. Johnston reported some results of a 6-borehole tiltmeter array approximately $5 \mathrm{~km}$ apart on alternate sides of the San Andreas fault. These instruments have been producing continuous tilt records for five months at tidal sensitivity, and secular tilt has, in general, been perpendicular to the fault. Of the few earthquakes that have occurred within two source dimensions of an instrument, all have produced a reversal of the secular tilt component parallel to the fault.

Finally, K.L. Cook discussed possible creep followed by stick slip earthquakes along the Wasatch fault zone in Utah.

Studies.' Contributed papers on all topics of concern to the sections of AGU will also be welcomed.

Unless otherwise specified, fifteen minutes will be allowed for each presentation. Slide projectors $(35 \mathrm{~mm})$ will be available, and other projection equipment can be obtained on request in advance. The deadline for abstracts is September 13.

The meeting, to be held at the Joint Center for Graduate Studies in Richland, Washington, will include an invited session on the opening day titled 'Geophysical Aspects of Nuclear Energy Production.' National experts have been asked to discuss selection of sites for nuclear plants, environmental heat sinks, management of radioactive wastes, and maintenance of operational safety.

Additional information on the conference can be obtained from H.B. Liemohn, Battelle-Northwest, Richland, Washington 99352. 